\title{
Correlated evolution of sternal keel length and ilium length in birds
}

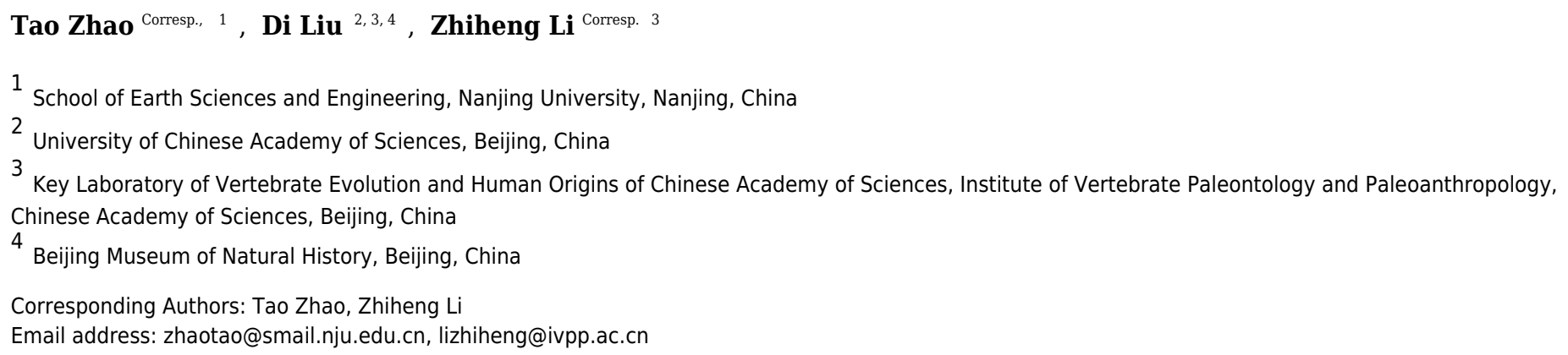

The interplay between the pectoral module (the pectoral girdle and limbs) and the pelvic module (the pelvic girdle and limbs) plays a key role in shaping avian evolution, but prior empirical studies on trait covariation between the two modules are limited. Here we empirically test whether (size-corrected) sternal keel length and ilium length are correlated during avian evolution using phylogenetic comparative methods. Our analyses on extant birds and Mesozoic birds both recover a significantly positive correlation. The results provide new evidence regarding the integration between the pelvic and pectoral modules. The correlated evolution of sternal keel length and ilium length may serve as a mechanism to cope with the effect on performance caused by a tradeoff in muscle mass between the pectoral and pelvic modules, via changing moment arms of muscles that function in flight and in terrestrial locomotion. 
3 Tao Zhao Corresp., 1 , Di Liu ${ }^{2,3,4}$, Zhiheng Li Corresp.,3

41 School of Earth Sciences and Engineering, Nanjing University, Nanjing, China

52 University of Chinese Academy of Sciences, Beijing, China

63 Key Laboratory of Vertebrate Evolution and Human Origins of Chinese Academy of Sciences, Institute

7 of Vertebrate Paleontology and Paleoanthropology, Chinese Academy of Sciences, Beijing, China

84 Beijing Museum of Natural History, Beijing, China

9

10 Corresponding Author: Tao Zhao

11 Email address: zhaotao@smail.nju.edu.cn

12 Corresponding Author: Zhiheng Li

Email address: lizhiheng@ivpp.ac.cn 


\section{Abstract}

24 The interplay between the pectoral module (the pectoral girdle and limbs) and the pelvic module (the pelvic girdle and limbs) plays a key role in shaping avian evolution, but prior empirical studies on trait covariation between the two modules are limited. Here we empirically test whether (size-corrected) sternal keel length and ilium length are correlated during avian evolution using phylogenetic comparative methods. Our analyses on extant birds and Mesozoic birds both recover a significantly positive correlation. The results provide new evidence regarding the integration between the pelvic and pectoral modules. The correlated evolution of sternal keel length and ilium length may serve as a mechanism to cope with the effect on performance caused by a tradeoff in muscle mass between the pectoral and pelvic modules, via changing moment arms of muscles that function in flight and in terrestrial locomotion. 
Introduction

Although the pectoral module (the pectoral girdle and limbs) and the pelvic module (the pelvic girdle and limbs) of birds are specialized for different functions, they are likely to be linked during evolution (Allen et al. 2013; Gatesy \& Dial 1996; Heers \& Dial 2015). This linkage could be a result of developmental and functional constraints (Allen et al. 2013; Young et al. 2005), as the pectoral and pelvic limbs share a broad range of development pathways, though they acquire distinct identity in adults in tetrapods (Young et al. 2005). Restricted by overall resources availability, pectoral and pelvic modules are negatively correlated in skeletal mass and muscle mass (Heers \& Dial 2015). In addition to simple resource partitioning, changes to one of the two modules, for example, an elongation of the forelimb, have implications for shifts in the position of center of mass, which can further alter the hindlimb posture and functions (Allen et al. 2013;

Dececchi \& Larsson 2013; Hutchinson \& Allen 2009). But the functional specialization could also weaken the integration between the pectoral and pelvic limbs, as suggested by morphometric analyses of avian and mammalian limbs (Bell et al. 2011; Schmidt \& Fischer 2009; Young et al. 2005). This conflict between drivers of limb evolution necessitates empirical studies to understand whether and how traits of pectoral and pelvic modules co-vary.

Along the theropod to avian lineage leading to the origin of crown birds, a series of morphological changes in the pectoral and pelvic girdles have previously been identified (Brusatte et al. 2015; Makovicky \& Zanno 2011). In the pectoral girdle, the changes include the enlargement of the sternum and keel (O'Connor et al. 
64 of an acrocoracoid process and the triosseal canal (Baier et al. 2007; Longrich 2009), the reorientation of

65 the glenoid fossa from laterally directed to dorsolaterally directed (Jenkins 1993), and the transformation

66 of the furcula from boomerang-shaped to U-shaped (Nesbitt et al. 2009; Zhou \& Zhang 2002). In the pelvic

67 girdle we find the elongation of the ilium and the loss of the pubic symphysis (Hutchinson 2001). Of these

68 changes two major derived features that characterize derived birds are the larger sternal keel and the longer

69 ilium (Hutchinson 2001; O'Connor et al. 2015). This pattern of similar first appearances of these two key

70 features could result from the correlated evolution between the sternal keel and the ilium, since pectoral

71 and pelvic modules are suggested to be integrated in evolution (Allen et al. 2013; Heers \& Dial 2015). Here

72 we compile morphometric data on extant birds and Mesozoic birds to empirically test this hypothesis based on sternal keel length and ilium length.

\section{Material and Methods}

\section{Data collection on extant birds}

We sampled 224 skeleton specimens with body mass data of 137 volant bird species from 45 families of 19 orders. All the specimens are housed in the collection of Beijing Museum of Natural History (Supporting Information Table S1). Sternal keel length and ilium length were taken with a digital caliper $( \pm 0.01 \mathrm{~mm})$

(Fig. 1). When multiple specimens were measured for a species, the mean values of those specimens were used. These variables were $\log 10$-transformed before subsequent analyses. 


\section{Phylogenetic comparative methods}

All analyses were carried out in R 3.3.3 (R Core Team) using packages “ape” (Paradis et al. 2004), "phytools" (Revell 2012) and "paleotree" (Bapst 2012). Figure 2 was created using "ggplot2” (Wickham 2009) and RColorBrewer (Neuwirth 2014).

\section{Phylogeny and size-correction}

We used 1000 time-calibrated phylogenetic trees for the 137 species included in our study from birdtree.org (Jetz et al. 2012). Phylogenetic size-correction of log10-transformed ilium length and keel length was conducted using the function phyl.resid in the "phytools" (Revell 2012).

\section{Evolutionary rate matrix}

Under the assumption of Brownian motion model, the variance of a trait at a given time interval is equal to the length of the time interval times the Brownian motion rate parameter, $\sigma^{2}$. The multivariate Brownian motion is governed by the evolutionary rate matrix, which contains the evolutionary variances or rates $\left(\sigma^{2}\right)$ for individual characters on its diagonals and the evolutionary covariances on its off-diagonals (Revell \& Collar 2009; Revell \& Harmon 2008). The Pearson correlation coefficient (r) can be calculated based on these values. This analysis was implemented using the function evol.vev in the "phytools" (Revell 2012). The Pearson correlation coefficients from iterations across the 1000 trees were averaged, 
106

107

108

109

110

111

112

113

114

115

116

117

118

119

120

121

122

123

124

125

126

weighted by their Akaike weights based on AICc (Burnham \& Anderson 2002). As the Pearson correlation coefficient does not follow a normal distribution, Fisher transformation was used during the process.

\section{Mesozoic birds}

To determine whether keel length and ilium length are correlated during early evolution of birds, we sampled 10 Mesozoic avian species housed in the collection of Institute of Vertebrate Paleontology and Paleoanthropology, Chinese Academy of Sciences, Beijing, China. Sternal keel length, ilium length and femur length were measured (Supporting Information Table S1). They were log10-transformed before subsequent analyses. Calibration dates for these taxa were adapted from Wang \& Lloyd (2016a; 2016b). A phylogenetic tree including these 10 species was constructed manually based on a recent phylogenetic analysis (Wang \& Zhou 2017). The fossil bird tree was time-calibrated using the function timePaleoPhy with the "equal" method in the "paleotree" (Bapst 2012), with tip dates drawn randomly from a uniform distribution between the maximum and minimum dates, producing 1000 trees. The estimate of the evolutionary rate matrix was iterated across these 1000 trees to account for the uncertainty in timecalibration. The estimated correlation coefficients from 1000 iterations were averaged, weighted by Akaike weights.

\section{Results}

In extant birds, the correlation between sternal keel length and ilium length is 0.77 (95\% Confidence 
interval: 0.69 to 0.84$)$. Similarly, the correlation is 0.90 in Mesozoic birds (95\% Confidence interval: 0.61 to 0.98 ). Both are positive and statistically significant, as their $95 \%$ confidence intervals do not include 0 .

In the morphospace defined by sternal keel length and ilium length (Fig. 2), several outliers are identifiable in these extant birds. Phalacrocorax carbo deviates from other taxa by entering the upper-left space, indicating that it has relatively long ilia but a relatively short keel. By contrast, Brachyramphus marmoratus enters the lower right space, by having a relatively long keel but relatively short ilia. Gavia stellata also deviates from others, but it largely follows the pattern of a positive correlation between sternal keel length and ilium length.

In the phylomorphospace defined by sternal keel length and ilium length of Mesozoic birds (Fig. 3), the enantiornithines are located in the lower left part, while the ornithuromorphs in the upper right part, indicating that the ornithuromorphs have a longer keel and longer ilia than the contemporary enantiornithines. An exception is a recent described enantiornithine bird, Piscivorenantiornis inusitatus, which has relatively longer ilia than most ornithuromorphs except Iteravis huchzermeyeri. Piscivoravis lii differs from other ornithuromorphs in having a comparatively shorter keel and shorter ilia.

\section{Discussion}

146 Our results support the hypothesis that ilium length and sternal keel length are correlated during avian 147 evolution and further provide quantitative support of the integration between pelvic and pectoral modules 
148 (Allen et al. 2013; Gatesy \& Dial 1996; Heers \& Dial 2015). Among basal birds, an ossified sternal keel is

149 absent in Archaeopteryx, Jeholornis and Sapeornis, and only a faint keel is present in Confuciusornis

150 (Chiappe et al. 1999; O'Connor et al. 2015; Zheng et al. 2014). The keel is small and restricted to the caudal

151 part of the sternum in Early Cretaceous enantiornithines (O'Connor et al. 2011; Wang \& Zhou 2017; Zheng

152 et al. 2012), while comparatively larger in ornithuromorphs (e.g., Zhou \& Zhang 2001; Zhou \& Zhang

153 2006). Despite these differences, the recovered positive correlation between the sternal keel length and

154 ilium length based on data of enantiornithines and ornithuromorphs suggests that this pattern appears very early in avian evolution.

Heers \& Dial (2015) showed that the pectoral and pelvic modules are negatively correlated in muscle mass

and skeletal mass and suggested the tradeoff in investment is associated with a tradeoff in performance. In

other words, the less-invested module has to cope with a larger burden. The correlated evolution of sternal

keel length and ilium length may serve as a mechanism to offset, to some extent, the effect on performance

caused by the tradeoff in muscle mass via changing moment arms of pectoral muscles and hindlimb

muscles, because the torque produced by a muscle is determined by its mass and moment arm and the effect

caused by a decrease in the muscle mass can be offset by an increase in the muscle moment arm. This

requires that the mass and moment arm of a muscle can be modified independently to some extent. The

Though sternal keel length is correlated with the mass of these muscles $\left(\mathrm{R}^{2}=0.47\right.$; Wright et al. 2016), 
evolution of flight, birds have the potential to modify masses and moment arms of pectoral muscles independently. Indeed, long-distance migratory birds can adjust the mass of pectoral muscles during their

171 lifetime (Dietz et al. 2007; Lindstrom et al. 2000). Similarly, evolution of hindlimb functions may be achieved through changing the masses or moment arms of hindlimb muscles, though their relationship has not been empirically estimated. These inferences need to be tested in future studies.

In the sampled extant birds, two birds, i.e., Brachyramphus marmoratus and Phalacrocorax carbo, are major outliers from other taxa in the morphospace defined by sternal keel length and ilium length (Fig. 2).

As a wing-propelled diver, the elongated keel Brachyramphus marmoratus accommodates the enlarged $\mathrm{m}$.

181 (Storer 1945). The relatively long ilium in Phalacrocorax carbo is an adaptation of foot-propelled diving

(HiniĆ-Frlog \& Motani 2010). Its comparatively shorter sternal keel than that of other foot-propelled divers,

(Norberg 1990). Phalacrocorax carbo is an example of the evolution towards flightlessness with the pelvic 
190 guoi and Longirostravis hani) in that it has relatively longer ilia (Fig. 3). The functional significance of this

191 feature in P. inusitatus is unclear, but in extant birds it is associated with an aquatic lifestyle (HiniĆ-Frlog

192 \& Motani 2010; Stoessel et al. 2013). This provides additional evidence of its ecology besides the pellet

193 found associated with the holotype skeleton (Wang et al. 2016).

194

In summary, pectoral and pelvic modules are linked in a more complicated way than just negatively correlated in overall investment. Besides modifying moment arms of muscles, birds may change behaviors through avian eggs, the shape of which is suggested to be correlated with both the pelvic shape (Dyke \& Kaiser 2010; Mayr 2017) and flight ability (Stoddard et al. 2017). More integrative studies in the future can provide more insight into the relationship between pectoral and pelvic modules.

\section{Acknowledgements}

We thank Mr. Zhaohui Zeng for access to specimens housed in Beijing Museum of Natural History and Mr. Qiong Wang for taking the photo. Comments from Jonathan Mitchell and T. Alexander Dececchi improved the manuscript.

\section{References}

210 Allen V, Bates KT, Li Z, and Hutchinson JR. 2013. Linking the evolution of body shape and locomotor 
biomechanics in bird-line archosaurs. Nature 497:104-107. 10.1038/nature12059

http://www.nature.com/nature/journal/v497/n7447/abs/nature12059.html\#supplementary-information

Baier DB, Gatesy SM, and Jenkins FA. 2007. A critical ligamentous mechanism in the evolution of avian flight. Nature 445:307-310.

Bapst DW. 2012. paleotree: an R package for paleontological and phylogenetic analyses of evolution. Methods in Ecology and Evolution 3:803-807. 10.1111/j.2041-210X.2012.00223.x

Bell E, Andres B, and Goswami A. 2011. Integration and dissociation of limb elements in flying vertebrates: a comparison of pterosaurs, birds and bats. J Evol Biol 24:2586-2599. 10.1111/j.14209101.2011.02381.x

Brusatte Stephen L, O’Connor Jingmai K, and Jarvis Erich D. 2015. The Origin and Diversification of Birds. Current Biology 25:R888-R898. http://dx.doi.org/10.1016/j.cub.2015.08.003

Burnham KP, and Anderson DR. 2002. Model selection and multimodel inference: a practical informationtheoretic approach. New York: Springer-Verlag.

Chiappe LM, Ji S, and Ji Q. 1999. Anatomy and systematics of the Confuciusornithidae (Theropoda: Aves) from the late mesozoic of northeastern China. Bulletin of the American Museum of Natural History Number 242.

Cracraft J. 1974. Phylogeny and evolution of the ratite birds. Ibis 116:494-521. 10.1111/j.1474919X.1974.tb07648.x

Dececchi TA, and Larsson HCE. 2013. Body and limb size dissociation at the origin of birds: uncoupling allometric constraints across a macroevolutionary transition. Evolution 67:2741-2752. 10.1111/evo. 12150

Dietz MW, Piersma T, Hedenström A, and Brugge M. 2007. Intraspecific variation in avian pectoral muscle mass: constraints on maintaining manoeuvrability with increasing body mass. Functional Ecology 21:317-326.

Dyke GJ, and Kaiser GW. 2010. Cracking a developmental constraint: egg size and bird evolution. Records of the Australian Museum 62:207-216.

Gatesy SM, and Dial KP. 1996. Locomotor Modules and the Evolution of Avian Flight. Evolution 50:331340. $10.2307 / 2410804$

Heers AM, and Dial KP. 2015. Wings versus legs in the avian bauplan: development and evolution of alternative locomotor strategies. Evolution 69:305-320. 10.1111/evo.12576

HiniĆ-Frlog S, and Motani R. 2010. Relationship between osteology and aquatic locomotion in birds: determining modes of locomotion in extinct Ornithurae. J Evol Biol 23:372-385. 10.1111/j.14209101.2009.01909.x

Hutchinson JR. 2001. The evolution of pelvic osteology and soft tissues on the line to extant birds (Neornithes). Zoological Journal of the Linnean Society 131:123-168. 10.1111/j.10963642.2001.tb01313.x

Hutchinson JR, and Allen V. 2009. The evolutionary continuum of limb function from early theropods to birds. Naturwissenschaften 96:423-448. 10.1007/s00114-008-0488-3

Jenkins FA. 1993. The evolution of the avian shoulder joint. American Journal of Science 293:253-267. 10.2475/ajs.293.A.253

Jetz W, Thomas GH, Joy JB, Hartmann K, and Mooers AO. 2012. The global diversity of birds in space 
252

253

254

255

256

257

258

259

260

261

262

263

264

265

266

267

268

269

270

271

272

273

274

275

276

277

278

279

280

281

282

283

284

285

286

287

288

289

290

291

292

and

time.

Nature

491:444-448.

http://www.nature.com/nature/journal/v491/n7424/abs/nature1 1631.html\#supplementaryinformation

Kovacs CE, and Meyers RA. 2000. Anatomy and histochemistry of flight muscles in a wing-propelled diving bird, the Atlantic puffin, Fratercula arctica. J Morphol 244:109-125.

Lindstrom A, Kvist A, Piersma T, Dekinga A, and Dietz MW. 2000. Avian pectoral muscle size rapidly tracks body mass changes during flight, fasting and fuelling. Journal of Experimental Biology 203:913.

Livezey BC. 1992. Flightlessness in the Galápagos cormorant (Compsohalieus [Nannopterum] harrisi): heterochrony, giantism and specialization. Zoological Journal of the Linnean Society 105:155-224.

Longrich N. 2009. An ornithurine-dominated avifauna from the Belly River Group (Campanian, Upper Cretaceous) of Alberta, Canada. Cretaceous Research 30:161-177. http://dx.doi.org/10.1016/j.cretres.2008.06.007

Makovicky PJ, and Zanno LE. 2011. Theropod Diversity and the Refinement of Avian Characteristics. Living Dinosaurs: John Wiley \& Sons, Ltd, 9-29.

Mayr G. 2017. Evolution of avian breeding strategies and its relation to the habitat preferences of Mesozoic birds. Evolutionary Ecology 31:131-141. 10.1007/s10682-016-9872-1

Nesbitt SJ, Turner AH, Spaulding M, Conrad JL, and Norell MA. 2009. The theropod furcula. J Morphol 270:856-879. 10.1002/jmor.10724

Neuwirth E. 2014. RColorBrewer: ColorBrewer Palettes. R package version 1.1-2. https://CRAN.Rproject.org/package $=$ RColorBrewer

Norberg U. 1990. Vertebrate Flight: Mechanics, Physiology, Morphology, Ecology and Evolution.: Springer Berlin Heidelberg.

O'Connor JK, Chiappe LM, Gao C, and Zhao B. 2011. Anatomy of the Early Cretaceous enantiornithine bird Rapaxavis pani. Acta Palaeontologica Polonica 56:463-475. 10.4202/app.2010.0047

O'Connor JK, Zheng XT, Sullivan C, Chuong CM, Wang XL, Li A, Wang Y, Zhang XM, and Zhou ZH. 2015. Evolution and functional significance of derived sternal ossification patterns in ornithothoracine birds. J Evol Biol 28:1550-1567. 10.1111/jeb.12675

Paradis E, Claude J, and Strimmer K. 2004. APE: Analyses of Phylogenetics and Evolution in R language. Bioinformatics 20:289-290. 10.1093/bioinformatics/btg412

R Core Team. 2017. R: A language and environment for statistical computing. R Foundation for Statistical Computing, Vienna, Austria. URL https://www.R-project.org/.

Revell LJ. 2012. phytools: an R package for phylogenetic comparative biology (and other things). Methods in Ecology and Evolution 3:217-223. 10.1111/j.2041-210X.2011.00169.x

Revell LJ, and Collar DC. 2009. Phylogenetic analysis of the evolutionary correlation using likelihood. Evolution 63:1090-1100. 10.1111/j.1558-5646.2009.00616.x

Revell LJ, and Harmon LJ. 2008. Testing quantitative genetic hypotheses about the evolutionary rate matrix for continuous characters. Evolutionary Ecology Research 10:311-331.

Schmidt M, and Fischer MS. 2009. Morphological integration in mammalian limb proportions: dissociation between function and development. Evolution 63:749-766. 10.1111/j.1558-5646.2008.00583.x

Spear LB, and Ainley DG. 1997. Flight behaviour of seabirds in relation to wind direction and wing 
morphology. Ibis 139:221-233.

Stoddard MC, Yong EH, Akkaynak D, Sheard C, Tobias JA, and Mahadevan L. 2017. Avian egg shape: Form, function, and evolution. Science 356:1249.

Stoessel A, Kilbourne BM, and Fischer MS. 2013. Morphological integration versus ecological plasticity in the avian pelvic limb skeleton. J Morphol 274:483-495. 10.1002/jmor.20109

Storer RW. 1945. Structural Modifications in the Hind Limb in the Alcidae. Ibis 87:433-456. 10.1111/j.1474-919X.1945.tb01375.x

Wang M, and Lloyd GT. 2016a. Data from: Rates of morphological evolution are heterogeneous in Early Cretaceous birds. Dryad Data Repository. http://dx.doi.org/10.5061/dryad.c128h

Wang M, and Lloyd GT. 2016b. Rates of morphological evolution are heterogeneous in Early Cretaceous birds. Proceedings of the Royal Society B: Biological Sciences 283.

Wang M, and Zhou Z. 2017. A morphological study of the first known piscivorous enantiornithine bird from the Early Cretaceous of China. Journal of Vertebrate Paleontology:e1278702.

Wang M, Zhou Z, and Sullivan C. 2016. A Fish-Eating Enantiornithine Bird from the Early Cretaceous of China Provides Evidence of Modern Avian Digestive Features. Current Biology 26:1170-1176. https://doi.org/10.1016/j.cub.2016.02.055

Wickham H. 2009. ggplot2: Elegant Graphics for Data Analysis: Springer-Verlag New York.

Wright NA, Steadman DW, and Witt CC. 2016. Predictable evolution toward flightlessness in volant island birds. Proceedings of the National Academy of Sciences 113:4765-4770. 10.1073/pnas. 1522931113

Young NM, Hallgrímsson B, and Janis C. 2005. Serial homology and the evolution of mammalian limb covariation structure. Evolution 59:2691-2704.

Zheng X, O'Connor J, Wang X, Wang M, Zhang X, and Zhou Z. 2014. On the absence of sternal elements in Anchiornis (Paraves) and Sapeornis (Aves) and the complex early evolution of the avian sternum. Proceedings of the National Academy of Sciences 111:13900-13905. 10.1073/pnas.1411070111

Zheng X, Wang X, O'Connor J, and Zhou Z. 2012. Insight into the early evolution of the avian sternum from juvenile enantiornithines. Nat Commun 3:1116.

Zhou Z, and Zhang F. 2001. Two new ornithurine birds from the Early Cretaceous of western Liaoning, China. Chinese Science Bulletin 46:1258-1264. 10.1007/BF03184320

Zhou Z, and Zhang F. 2002. A long-tailed, seed-eating bird from the Early Cretaceous of China. Nature 418:405-409. 10.1038/nature00923

Zhou Z, and Zhang F. 2006. A beaked basal ornithurine bird (Aves, Ornithurae) from the Lower Cretaceous of China. Zoologica Scripta 35:363-373. 10.1111/j.1463-6409.2006.00234.x 


\section{Figure 1}

Measurements used in this study (Phasianus colchicus, BMNH 214941, in lateral view).

Photo credit: Qiong Wang.

*Note: Auto Gamma Correction was used for the image. This only affects the reviewing manuscript. See original source image if needed for review. 


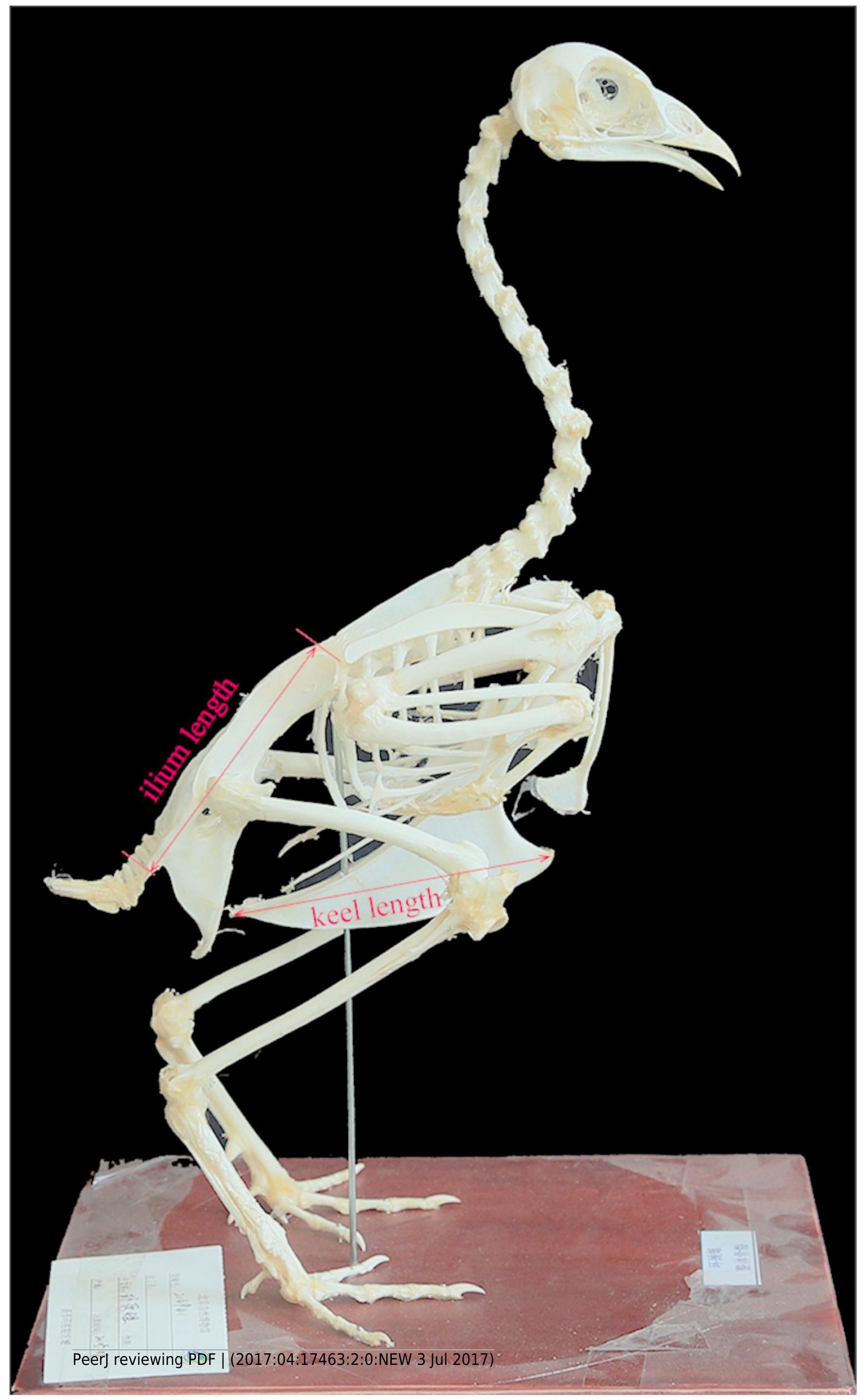


Figure 2 (on next page)

Morphospace defined by sternal keel length and ilium length showing distribution of extant birds.

Silhouettes were modified from images licensed under creative commons: Gavia stellata (Tony Morris, https://www.flickr.com/photos/tonymorris/429265757/); Phalacrocorax carbo (Tony Morris, https://www.flickr.com/photos/tonymorris/6102041629/); Remiz pendulinus (Michele Lamberti, https://www.flickr.com/photos/60740813@N04/8360911825/);

Brachyramphus marmoratus (J. J. Audubon, http://www.faculty.ucr.edu/ legneref/birds/jpg/avex178.jpg). 


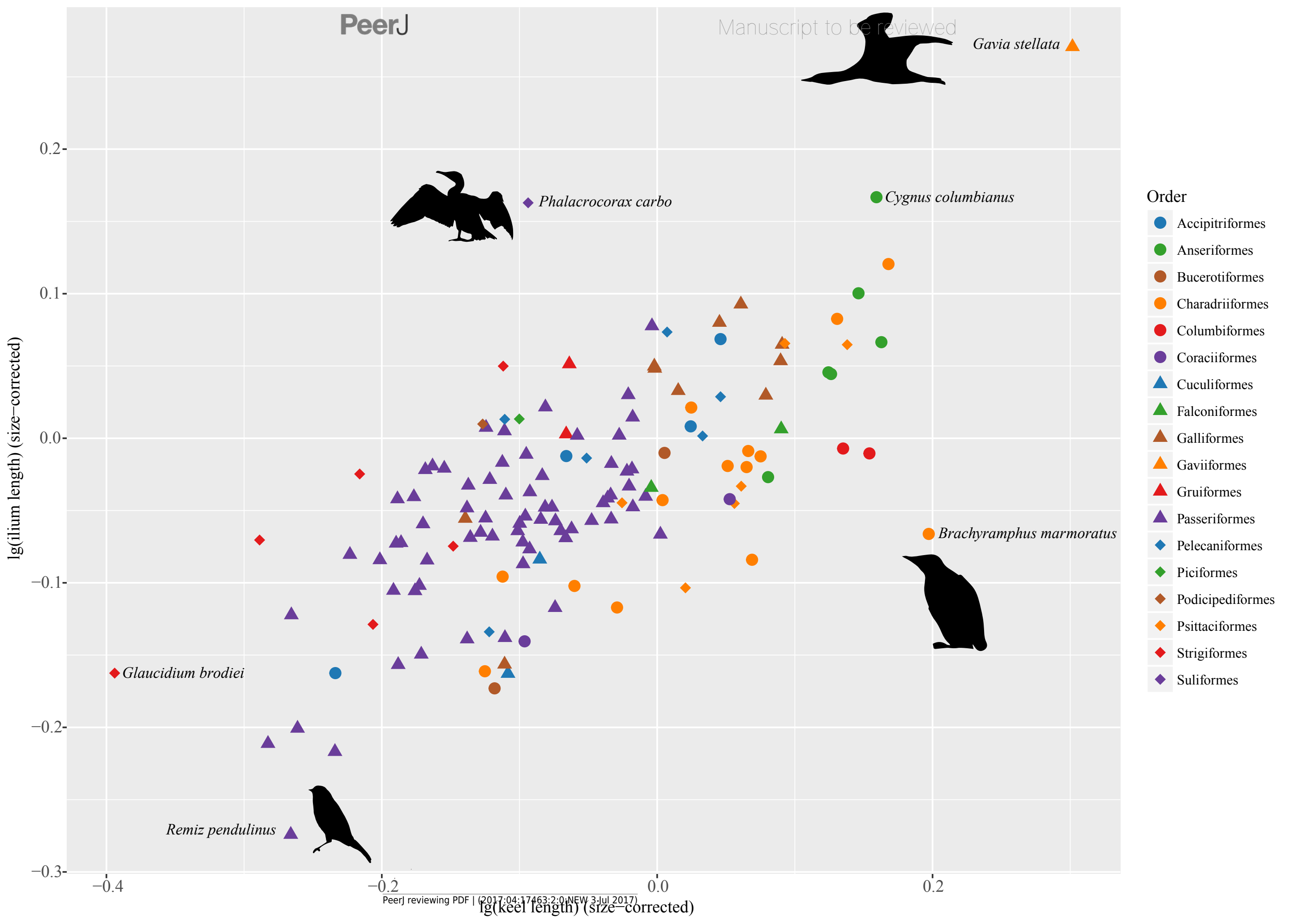


Figure 3 (on next page)

Phylomorphospace depicting a Mesozoic bird tree in shape space defined by sternal keel length and ilium length. 
